\title{
Clinical and histological heterogeneity of congenital hyperinsulinism due to paternally inherited heterozygous ABCC8IKCNJ11 mutations
}

\author{
Ved Bhushan Arya 1,2,*, Maria Guemes ${ }^{1,2, *}$, Azizun Nessa1, Syeda Alam², \\ Pratik Shah ${ }^{1,2}$, Clare Gilbert ${ }^{2}$, Senthil Senniappan ${ }^{1,2}$, Sarah E Flanagan ${ }^{3}$, Sian Ellard ${ }^{3}$ \\ and Khalid Hussain ${ }^{1,2}$ \\ 'Developmental Endocrinology Research Group, Clinical and Molecular Genetics Unit, Institute of Child Health, \\ University College London, 30 Guilford Street, London WC1N 1EH, UK, ${ }^{2}$ London Centre for Paediatric \\ Endocrinology, Great Ormond Street Hospital for Children, London WC1N 3JH, UK and ${ }^{3}$ Institute of Biomedical \\ and Clinical Science, University of Exeter Medical School, Exeter EX2 5DW, UK \\ *(V B Arya and M Guemes contributed equally to this work)
}

Correspondence
should be addressed
to K Hussain
Email
Khalid.Hussain@ucl.ac.uk

\begin{abstract}
Context: Congenital hyperinsulinism (CHI) has two main histological types: diffuse and focal. Heterozygous paternally inherited $A B C C 8 / K C N J 11$ mutations (depending upon whether recessive or dominant acting and occurrence of somatic maternal allele loss) can give rise to either phenotype. However, the relative proportion of these two phenotypes in a large cohort of $\mathrm{CHI}$ patients due to paternally inherited heterozygous $A B C C 8 / K C N J 11$ mutations has not been reported.

Objective: The purpose of this study is to highlight the variable clinical phenotype and to characterise the distribution of diffuse and focal disease in a large cohort of $\mathrm{CHI}$ patients due to paternally inherited heterozygous $A B C C 8 / K C N J 11$ mutations. Design: A retrospective chart review of the $\mathrm{CHI}$ patients due to heterozygous paternally inherited $A B C C 8 / K C N J 11$ mutations from 2000 to 2013 was conducted.

Results: Paternally inherited heterozygous $A B C C 8 / K C N J 11$ mutations were identified in $53 \mathrm{CHI}$ patients. Of these, 18 (34\%) either responded to diazoxide or resolved spontaneously. Fluorine-18 L-3, 4-dihydroxyphenylalanine positron emission tomography computerised tomography $\left({ }^{18} \mathrm{~F}\right.$ DOPA-PET CT) scanning in $3 / 18$ children showed diffuse disease. The remaining $35(66 \%)$ diazoxide-unresponsive children either had pancreatic venous sampling $(n=8)$ or ${ }^{18} \mathrm{~F}$ DOPA-PET CT $(n=27)$. Diffuse, indeterminate and focal disease was identified in 13,1 and 21 patients respectively. Two patients with suspected diffuse disease were identified to have focal disease on histology.

Conclusions: Paternally inherited heterozygous $A B C C 8 / K C N J 11$ mutations can manifest as a wide spectrum of $\mathrm{CHI}$ with variable ${ }^{18} \mathrm{~F}$ DOPA-PET CT/histological findings and clinical outcomes. Focal disease was histologically confirmed in $24 / 53(45 \%)$ of $\mathrm{CHI}$ patients with paternally inherited heterozygous $A B C C 8 / K C N J 11$ mutations.
\end{abstract}

\section{Introduction}

Congenital hyperinsulinism (CHI) is one of the main causes of hypoglycaemia and is characterised by inappropriate insulin secretion (1). Mutations in nine different genes (ABCC8, KCNJ11, GLUD1, GCK, HADH, SLC16A1,
UCP2, HNF4A and HNF1A) have been reported so far as the genetic causes of $\mathrm{CHI}(1,2)$. The pancreatic $\beta$-cell ATPsensitive potassium channel $\left(\mathrm{K}_{\mathrm{ATP}}\right.$ channel) regulates glucose-mediated insulin release and is composed of two 
subunits: Kir6.2 encoded by KCNJ11 and SUR1 encoded by $A B C C 8$ gene (2). Both genes are localised in the $11 \mathrm{p} 15.1$ region and mutations in these accounts for the majority of CHI patients $(3,4,5,6,7,8,9,10,11)$.

There are two main forms of CHI (focal and diffuse) that are clinically identical but differ in histology, underlying genetic mechanism and management. In diffuse CHI, histologically there is an increase in the $\beta$-cell nuclear size throughout the pancreas. Diffuse $\mathrm{CHI}$ is genetically heterogeneous and most commonly due to mutations in $A B C C 8$ or $K C N J 11$ genes $(3,12,13,14,15)$. Diazoxide, an agonist that targets the SUR1 subunit, is usually ineffective in patients with autosomal recessive form of $A B C C 8$ or KCNJ11 mutations. The management of the medically unresponsive diffuse $\mathrm{CHI}$ patients involves near-total pancreatectomy.

The focal lesions are characterised by nodular hyperplasia of islet-like cell clusters with ductuloinsular complexes and scattered giant $\beta$-cell nuclei with normal surrounding tissue (16). The focal $\mathrm{CHI}$ results from a paternally inherited heterozygous ABCC8/KCNJ11 mutation together with a somatic loss of the maternal chromosome in the 11 p15 region (most likely caused by paternal isodisomy) $(16,17)$. The resulting loss of heterozygosity $(\mathrm{LOH})$ renders the $\beta$-cells biallelic for the abnormal foci, altering the $\mathrm{K}_{\mathrm{ATP}}$ channel and resulting in dysregulated insulin secretion within the focal lesion $(16,17,18)$. The consequent imbalance in the expression of adjacent imprinted genes implicated in cell proliferation (such as CDKN1C and H19 normally expressed from the maternal allele and IGF2 paternally expressed) within the $11 \mathrm{p} 15.5$ region leads to focal islet cell adenomatous hyperplasia $(19,20,21,22)$. Focal CHI is usually medically unresponsive, although diazoxide-responsive focal $\mathrm{CHI}$ has been recently described (23). Targeted surgical removal of the lesion will cure the patient.

Fluorine-18 L-3, 4-dihydroxyphenylalanine positron emission tomography computerised tomography $\left({ }^{18} \mathrm{~F}\right.$ DOPA-PET CT) scan can help to differentiate the focal from diffuse forms of $\mathrm{CHI}$ and aids in the clinical management of these patients (24). Before the advent of ${ }^{18}$ F DOPA-PET CT, pancreatic venous sampling (PVS) and selective pancreatic arterial calcium stimulation with hepatic venous sampling (ASVS) were used to differentiate between the two subtypes $(25,26)$. A recent systematic review and meta-analysis has found ${ }^{18} \mathrm{~F}$ DOPA-PET CT to be far superior to PVS and ASVS in diagnosing and localising focal CHI (27).

Patients with $\mathrm{CHI}$ associated with heterozygous paternally inherited $A B C C 8 / K C N J 11$ mutations may or may not have the second hit of somatic maternal allele loss in the pancreatic $\beta$-cell. Accordingly, these patients can either have focal or diffuse disease. Furthermore, diffuse disease can either be diazoxide-responsive or unresponsive depending on the underlying molecular basis of the mutation and other unclear genetic or environmental influences (28). There are isolated case reports of heterozygous paternally inherited $A B C C 8$ / KCNJ11 mutations leading to diffuse CHI in the literature $(3,10,29,30)$. The proportion of patients with paternally inherited heterozygous $A B C C 8 / K C N J 11$ mutations who develop focal $\mathrm{CHI}$ has not been reported in any study so far. Herein, we describe the heterogeneous clinical presentation and the histological basis of a relatively large cohort of patients with heterozygous paternally inherited $A B C C 8 / K C N J 11$ mutations. We also report the proportion of focal and diffuse disease in a large cohort of $\mathrm{CHI}$ patients with paternally inherited heterozygous $A B C C 8 / K C N J 11$ mutations.

\section{Subjects and methods}

The study was approved by the Ethics Committee of Great Ormond Street Children's Hospital and the Institute of Child Health. Informed written consent was obtained from the parents of children enrolled for molecular genetic testing for $\mathrm{CHI}$ ( $A B C C 8 / K C N J 11$ sequencing).

This is a descriptive study of the clinical characteristics of children with $\mathrm{CHI}$ due to paternally inherited heterozygous $A B C C 8 / K C N J 11$ mutations. Clinical presentation, disease course and outcome for consecutive patients with $\mathrm{CHI}$ associated with paternally inherited heterozygous ABCC8/KCNJ11 mutations between the years 2000 and 2013 were retrospectively reviewed.

CHI was diagnosed by a controlled fasting test that demonstrated an inappropriately detectable serum insulin and/or C-peptide concentration and/or inappropriately low $\beta$-hydroxybutyrate and non-esterified fatty acids concentrations in the presence of hypoglycaemia (plasma glucose concentration $<3.0 \mathrm{mmol} / \mathrm{l}$ ). The patients with confirmed diagnosis of CHI underwent molecular genetic analysis after informed consent (see below). Diazoxide (5-15 mg/kg per day in three divided doses) was commenced as the first-line medical treatment. The patients were defined as diazoxide unresponsive if age appropriate fasting tolerance could not be achieved by treatment with $15 \mathrm{mg} / \mathrm{kg}$ per day diazoxide for a minimum of 5 days. Diazoxide-unresponsive patients associated with paternally inherited heterozygous ABCC8/KCNJ11 mutation underwent further investigations (PVS or 
${ }^{18} \mathrm{~F}$ DOPA-PET CT) to differentiate between focal and diffuse disease. PVS was performed and interpreted as described previously by de Lonlay-Debeney et al. (26). The detailed protocol used for ${ }^{18}$ F DOPA-PET CT and analysis of the images has already been described (31).

Diazoxide-unresponsive diffuse disease was managed by octreotide injections $(5-30 \mu \mathrm{g} / \mathrm{kg}$ per day in three to four divided doses \pm near-total pancreatectomy along with carbohydrate-rich feeds. The focal disease was managed with the resection of the focal lesion or partial pancreatectomy. Post-surgery, glycaemic control was periodically assessed by 24 -h blood glucose profile and controlled fast to ensure cure of the focal $\mathrm{CHI}$ and appropriate control of diffuse $\mathrm{CHI}$.

\section{Genetic testing}

Genomic DNA was extracted from peripheral leukocytes using standard procedures. The single-coding exon of the KCNJ11 gene and the 39 exons of the ABCC8 gene were amplified using the PCR. Unidirectional sequencing was performed using universal M13 primers and a Big Dye Terminator Cycle Sequencing Kit v3.1 (Applied Biosystems) according to the manufacturer's instructions. The reactions were analysed on an ABI 3730 Capillary Sequencer (Applied Biosystems) and the sequences were compared with the reference sequences (NM_000525 and NM_000352.2) using Mutation Surveyor v3.24 (SoftGenetics, PA, USA). Dosage analyses by multiplex ligation-dependent probe amplification were done in patients with a heterozygous $A B C C 8 / K C N J 11$ mutation and diffuse disease on ${ }^{18} \mathrm{~F}$ DOPA-PET scan/PVS (32).

$\mathrm{LOH}$ was investigated by microsatellite analysis of DNA extracted from paraffin-embedded pancreatic tissue and peripheral leukocytes, mainly when there was a discrepancy between the histology and ${ }^{18} \mathrm{~F}$ DOPA-PET CT/PVS result. Six markers (D11S2071, D11S1964, D11S419, D11S1397, D11S1888 and D11S4138) spanning chromosome 11p15.1-11p15.5 were amplified by PCR and allele peak heights were compared using GeneMarker v1.85 (SoftGenetics).

\section{Results}

Over a period of 14 years (2000-2013), more than 300 children with confirmed biochemical and genetic diagnosis of CHI were managed in our centre. Of these, 53 children had paternally inherited heterozygous $A B C C 8 / K C N J 11$ mutation (ABCC8, 42 and KCNJ11, 11). Of the 35 different $A B C C 8$ mutations seen in 42 patients, 19 affected a single amino acid (missense or in-frame deletion/insertion). Of the ten different KCNJ11 mutations seen in 11 patients, eight affected a single amino acid (missense or in-frame deletion/insertion), one was a frame shift mutation and one was a non-stop codon mutation resulting in extension of the Kir6.2 protein sequence by three amino acids (Fig. 1). As shown in Fig. 1, mutations occurred throughout SUR1 and Kir6.2.

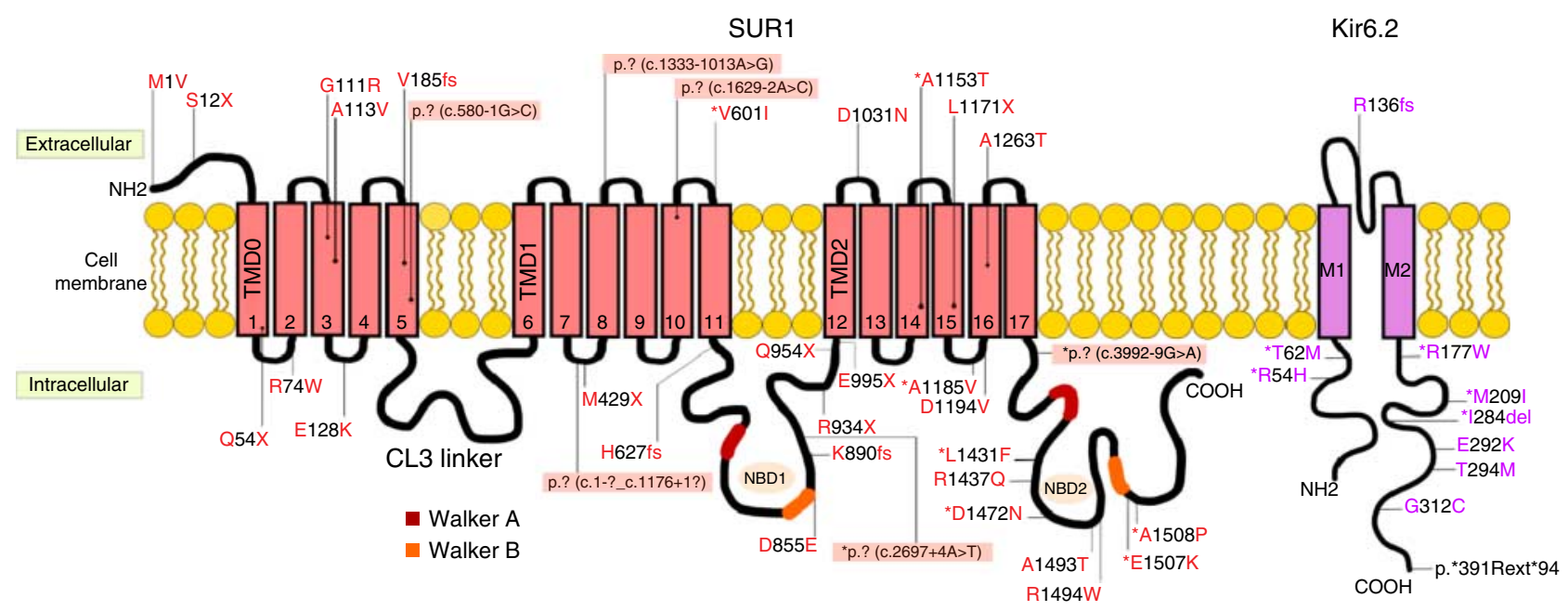

\section{Figure 1}

Paternal mutations mapped onto the SUR1 and Kir6.2 protein. All SUR1 intronic splice site mutation mutants have been highlighted in red. All mutants with * are responsive to diazoxide (transmembrane domain (TMD) and nucleotide-binding domain (NBD)). A full colour version of this figure available via http://dx.doi.org/10.1530/EJE-14-0353. 


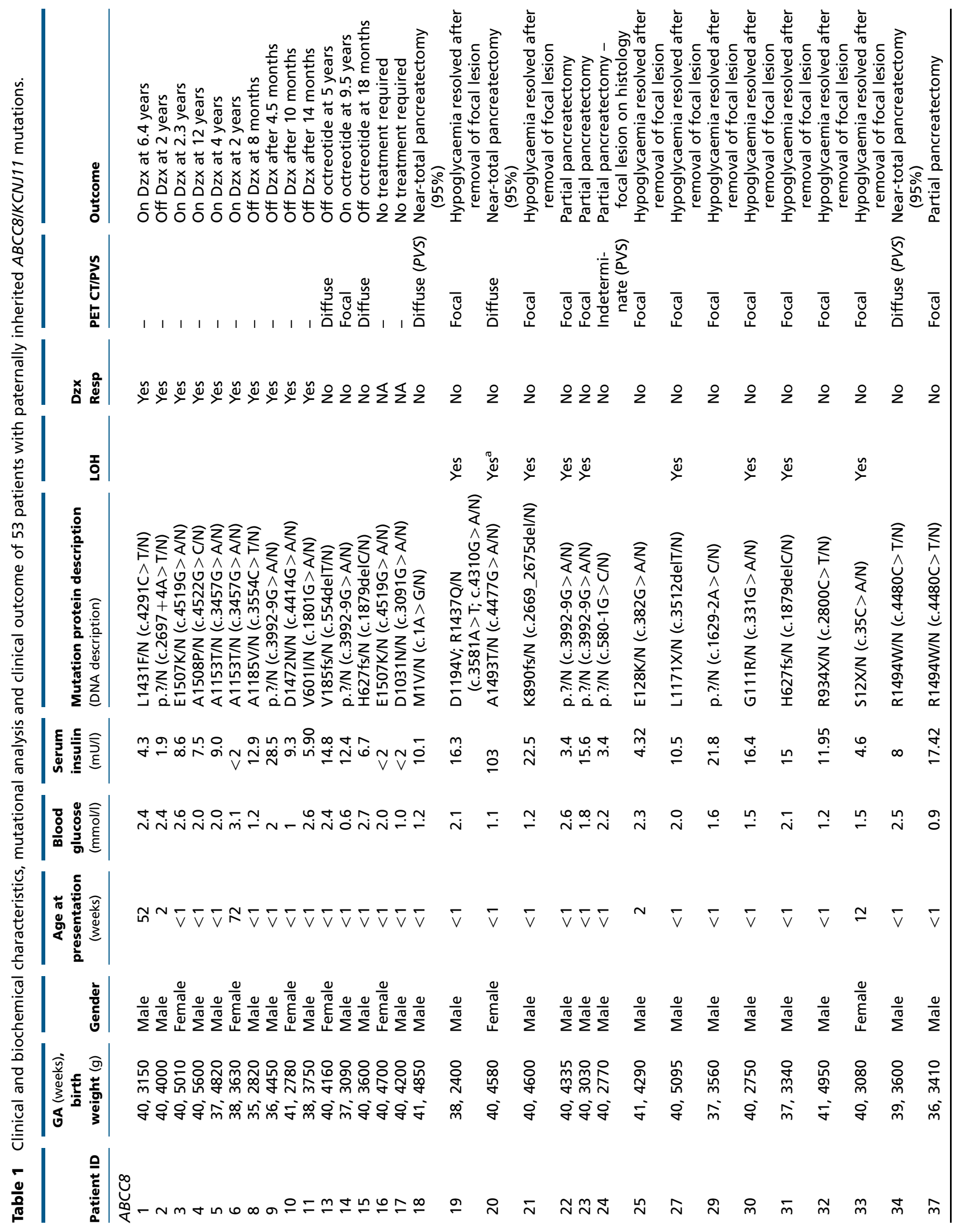



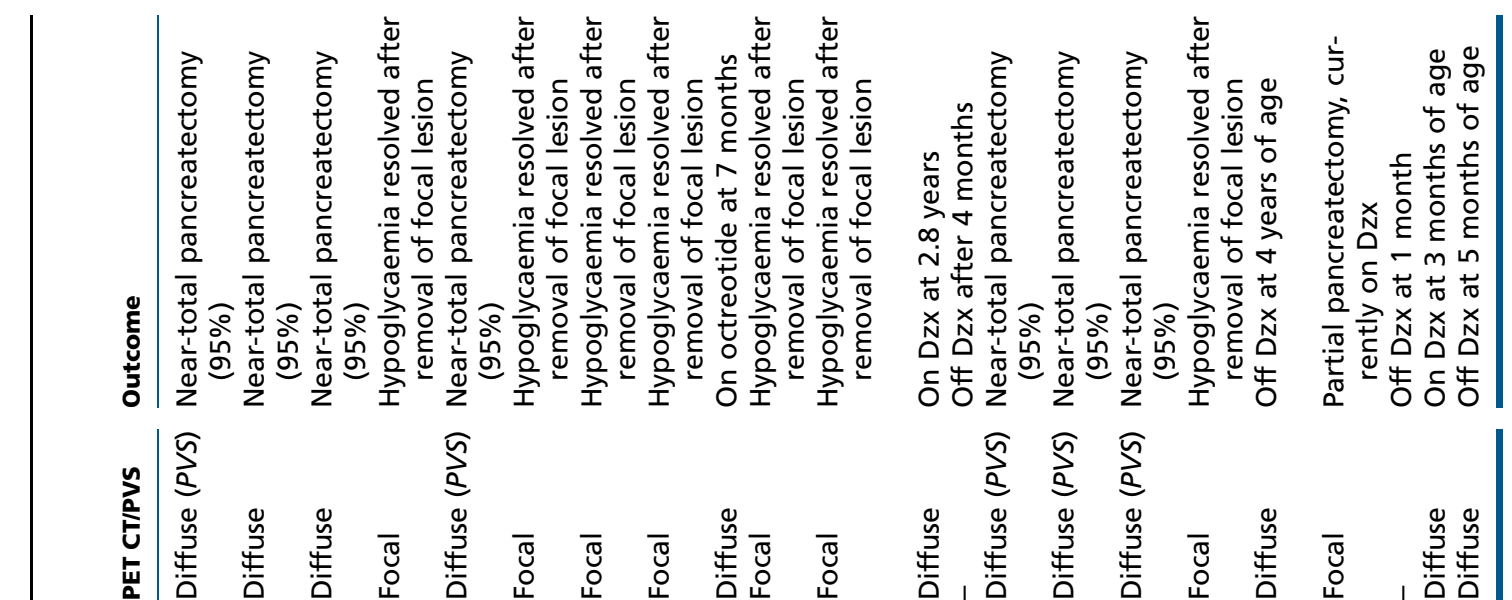

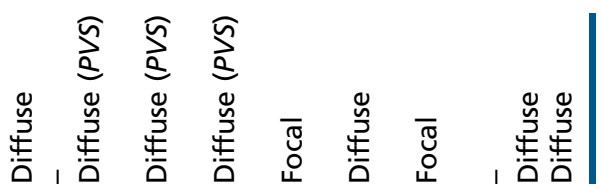

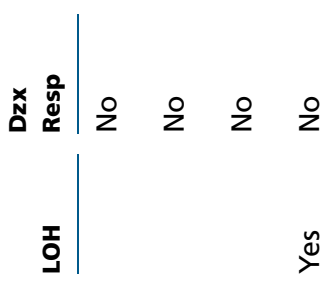

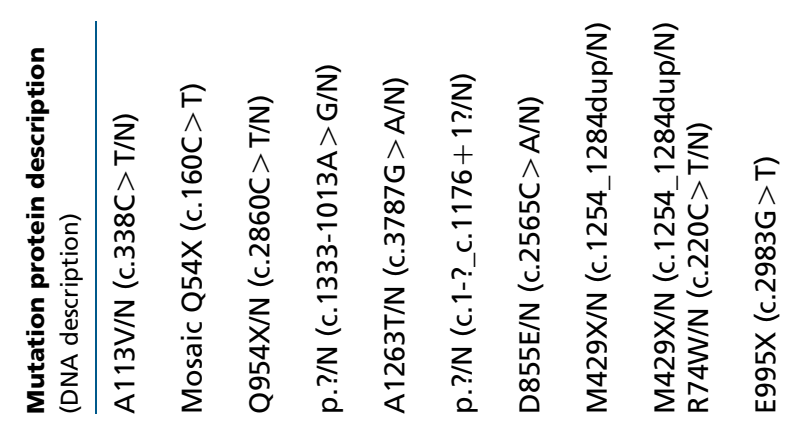

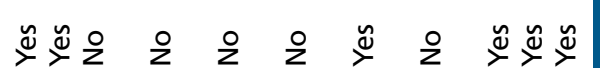

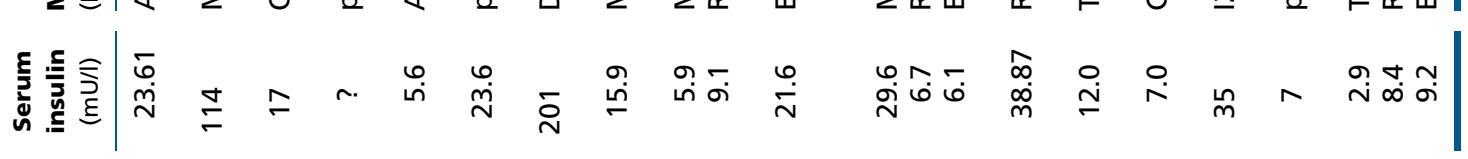

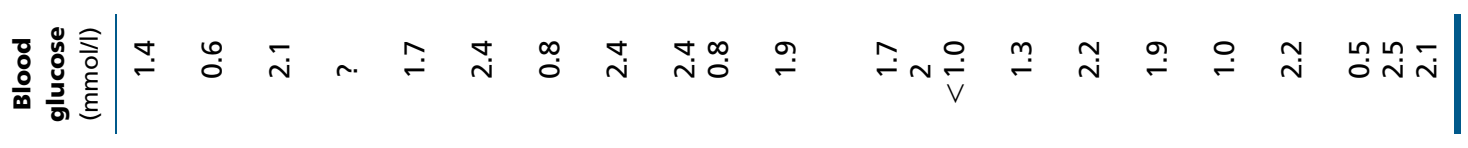

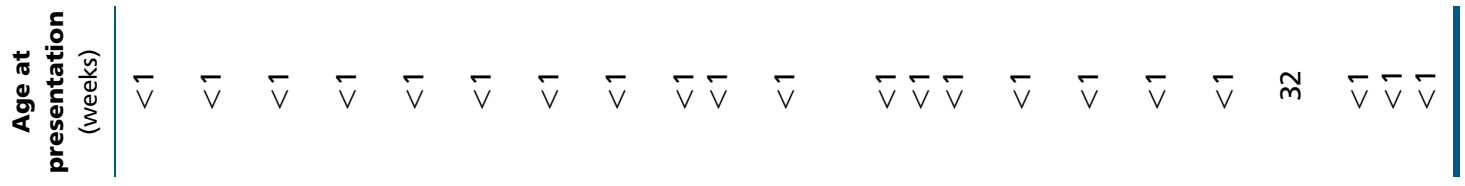

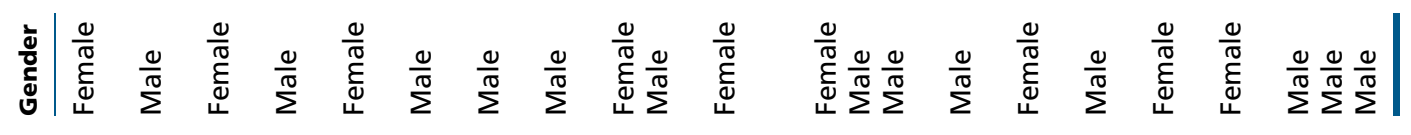

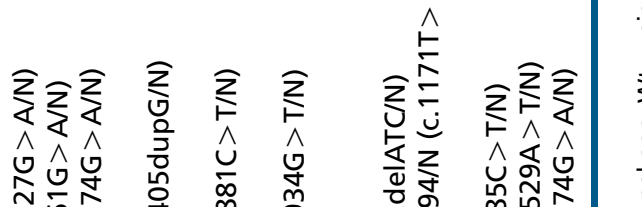

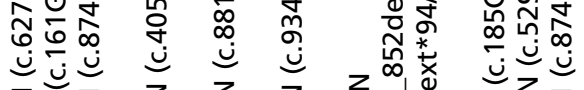

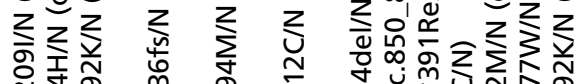

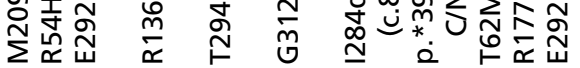




\section{Clinical and biochemical characteristics}

The mean ( \pm 2 s.D.) gestational age and birth weight of our cohort was $38.9( \pm 1.8)$ weeks and $3980( \pm 760) \mathrm{g}$ respectively. Of these, 19 infants (36\%) were macrosomic (birth weight $>2$ s.D.) at birth. The gender distribution was 37 males and 16 females. The majority of patients in our cohort were of Caucasian descent. Only one proband was a product of the consanguineous marriage. There were two pairs of two siblings and the rest of the cohort was unrelated. The median age of presentation with hypoglycaemia was $<1$ week (range $<1-130$ weeks). More than $85 \%(46 / 53)$ patients presented with hypoglycaemia within first week of life. The mean $( \pm$ s.D.) serum insulin during hypoglycaemia was $21.1( \pm 34.2) \mathrm{mU} / \mathrm{l}$. In three infants in whom serum insulin was undetectable, C-peptide level was inappropriately elevated for the blood glucose measurement. The serum ammonia was within normal range and $\beta$-hydroxybutyrate/non-esterified fatty acids were inappropriately low in all children (Table 1).

\section{Clinical course, ${ }^{18} \mathrm{~F}$ DOPA-PET CT and PVS findings and final outcome}

Diazoxide-responsive group - In two (4\%) patients (Table 1: patients 16 and 17), CHI resolved spontaneously within few weeks before investigations were repeated in our centre (Fig. 2). Previous functional work has established milder disease phenotype with a mutation seen in one of these two patients (ABCC8 (E1507K)) (33). The mutation identified in the second patient (ABCC8 $(D 1031 N))$ is not reported in dbSNP and predicted to be disease causing (Table 2 ).

Sixteen patients (30\%) with presumably diffuse CHI responded to diazoxide treatment (Fig. 2). In three patients from diazoxide-responsive group who underwent ${ }^{18} \mathrm{~F}$ DOPA-PET CT, diffuse uptake throughout the pancreas was noticed. Nine patients (17\%) successfully managed to come off diazoxide treatment after a variable period of time. The remaining seven (13\%) patients were on diazoxide for a median duration of 2.8 years (range 3 months-12 years) at the time of writing.

The mutations in this subgroup are predicted to be pathogenic by various mutation prediction programmes (Table 2) $(34,35)$.

Diazoxide-unresponsive group $>$ The remaining 35 (66\%) patients were unresponsive to maximum doses of diazoxide and were investigated either by using PVS $(n=8)$ or ${ }^{18}$ F DOPA-PET CT scan $(n=27)$.

PVS was suggestive of diffuse disease in seven patients and no differentiation between focal and diffuse was

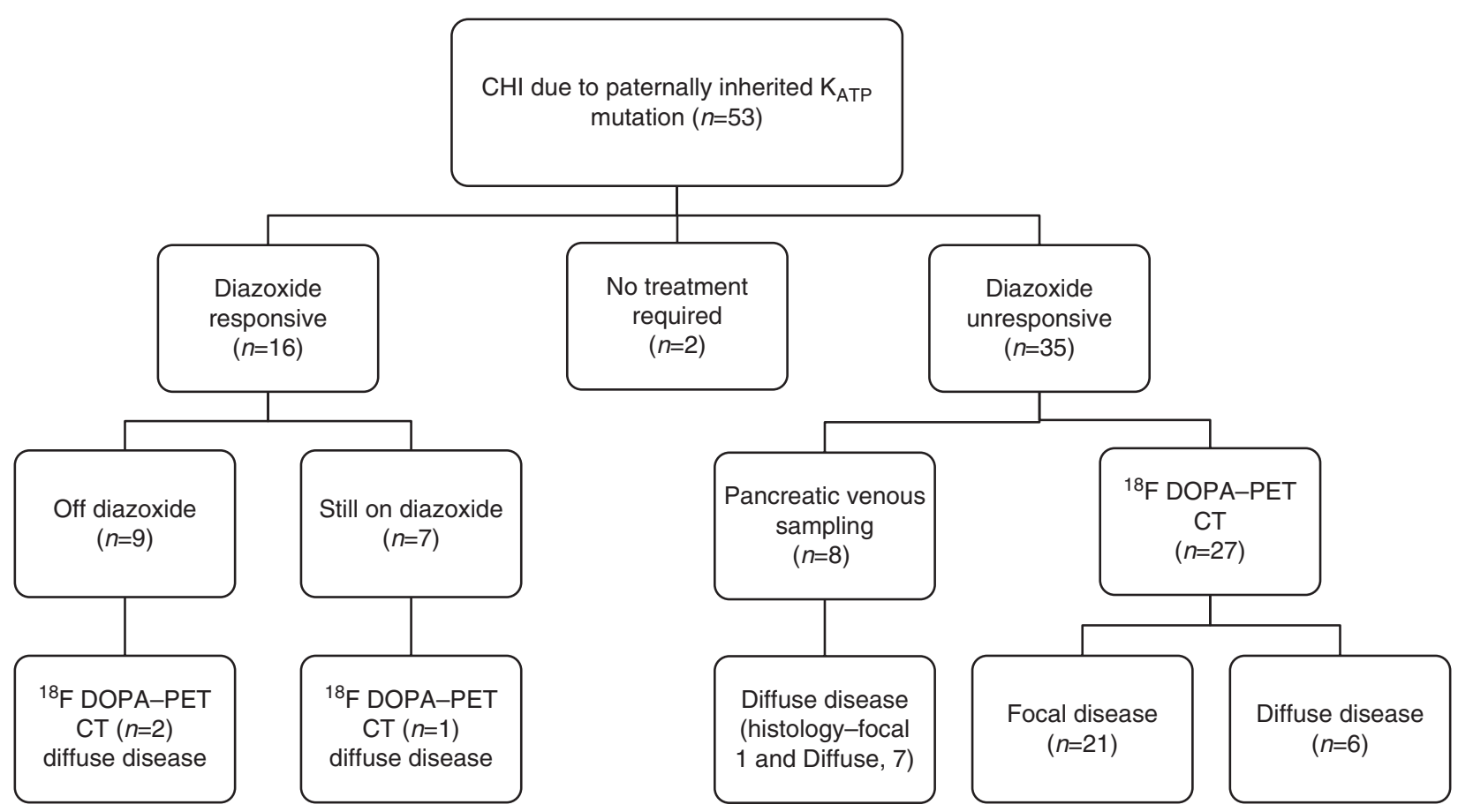

Figure 2

Clinical course, ${ }^{18} \mathrm{~F}$ DOPA-PET CT/pancreatic venous sampling findings and outcome. 
Table 2 In silico pathogenicity prediction of diazoxide-responsive patients' mutations.

\begin{tabular}{|c|c|c|c|c|c|}
\hline \multirow[b]{2}{*}{ Mutation } & \multicolumn{4}{|c|}{ Prediction } & \multirow{2}{*}{$\begin{array}{c}\text { Mutation } \\
\text { previously reported }\end{array}$} \\
\hline & Found in dbSNP & Provean & SIFT & MutationTaster & \\
\hline \multicolumn{6}{|l|}{$A B C C 8$} \\
\hline L1431F (c.4291C>T) & No & Deleterious & Damaging & Disease causing & $(38)^{a}$ \\
\hline p.? $($ c.2697+4A > T) & No & Not available & Not available & Disease causing & Novel \\
\hline E1507K (c.4519G >A) & Yes & Deleterious & Damaging & Disease causing & (32) \\
\hline A1508P (c.4522G >C) & No & Deleterious & Damaging & Disease causing & $(38)^{a}$ \\
\hline A1153T (c.3457G >A) & No & Deleterious & Damaging & Disease causing & Novel \\
\hline A1185V (c.3554C > T) & No & Neutral & Damaging & Disease causing & Novel \\
\hline p.? $(c .3992-9 \mathrm{G}>\mathrm{A})$ & No & Not available & Not available & Disease causing & $(5)^{a}$ \\
\hline $\mathrm{D} 1472 \mathrm{~N}(\mathrm{c} .4414 \mathrm{G}>\mathrm{A})$ & Yes & Deleterious & Damaging & Disease causing & $(24)^{a}$ \\
\hline V601I (c.1801G > A) & No & Neutral & Tolerated & Disease causing & Novel $^{a}$ \\
\hline V185fs (c.554delT) & Yes & Not available & Not available & Disease causing & Novel \\
\hline H627fs (c.1879delC) & No & Not available & Not available & Disease causing & $(9)^{a}$ \\
\hline $\mathrm{D} 1031 \mathrm{~N}(\mathrm{c} .3091 \mathrm{G}>\mathrm{A})$ & No & Neutral & Tolerated & Disease causing & Novel \\
\hline $\mathrm{M} 1 \mathrm{~V}(\mathrm{c} .1 \mathrm{~A}>\mathrm{G})$ & No & Neutral & Damaging & Disease causing & $(6)^{a}$ \\
\hline A1493T (c.4477G >A) & Yes & Deleterious & Damaging & Disease causing & $(14)^{a}$ \\
\hline $\mathrm{R} 1494 \mathrm{~W}(\mathrm{c} .4480 \mathrm{C}>\mathrm{T})$ & Yes & Deleterious & Damaging & Disease causing & $(25)^{a}$ \\
\hline \multicolumn{6}{|l|}{ KCNJ11 } \\
\hline M209I (c.627G >A) & No & Neutral & Damaging & Disease causing & Novel \\
\hline $\mathrm{R} 54 \mathrm{H}(\mathrm{c} .161 \mathrm{G}>\mathrm{A})$ & No & Deleterious & Damaging & Disease causing & Novel $^{a}$ \\
\hline E292K (c.874G >A) & No & Deleterious & Damaging & Disease causing & Novel \\
\hline $\mathrm{T} 62 \mathrm{M}(\mathrm{c} .185 \mathrm{C}>\mathrm{T})$ & No & Deleterious & Damaging & Disease causing & (4) \\
\hline $\mathrm{R} 177 \mathrm{~W}$ (c.529A > T) & No & Deleterious & Damaging & Disease causing & Novel \\
\hline
\end{tabular}

${ }^{\mathrm{a}}$ These patients were included in reference (3).

possible in one patient. The suspected diffuse disease patients were managed with near-total pancreatectomy. Although histology confirmed diffuse disease in six patients, there was one patient who had focal adenomatous hyperplasia which was presumably missed on PVS. The patient with indeterminate PVS underwent partial pancreatectomy and focal lesion was seen on the histology of the resected pancreas.

Of the 27 patients who were investigated with ${ }^{18} \mathrm{~F}$ DOPA-PET scan, focal uptake was seen in 21 and diffuse uptake in six patients (Fig. 3). The focal lesion was successfully managed either with lesionectomy $(n=16)$ or partial pancreatectomy $(n=4)$. One patient was managed successfully with octreotide injections.

The patients with diffuse tracer pancreatic uptake were either managed with near-total pancreatectomy $(n=3)$ or octreotide injections $(n=3)$. One patient from this subgroup had atypical histology with pancreatic $\beta$-cell enlargement in parts of body and head of the pancreas due to mosaic interstitial paternal uniparental isodisomy for chromosome 11p15.1 (36).

\section{Discussion}

This study reports the proportion of focal disease in a large cohort of patients with $\mathrm{CHI}$ associated with paternally inherited heterozygous $A B C C 8 / K C N J 11$ mutations. In addition, it highlights the clinical and histological heterogeneity of $\mathrm{CHI}$ associated with paternally inherited heterozygous $A B C C 8 / K C N J 11$ mutation.

Mutations in the $A B C C 8 / K C N J 11$, which account for the majority of genetically confirmed CHI cases, can either be biallelic or monoallelic (3, 4, 37). Biallelic $A B C C 8 / K C N J 11$ mutations result in diffuse CHI, whereas monoallelic mutations can either be asymptomatic

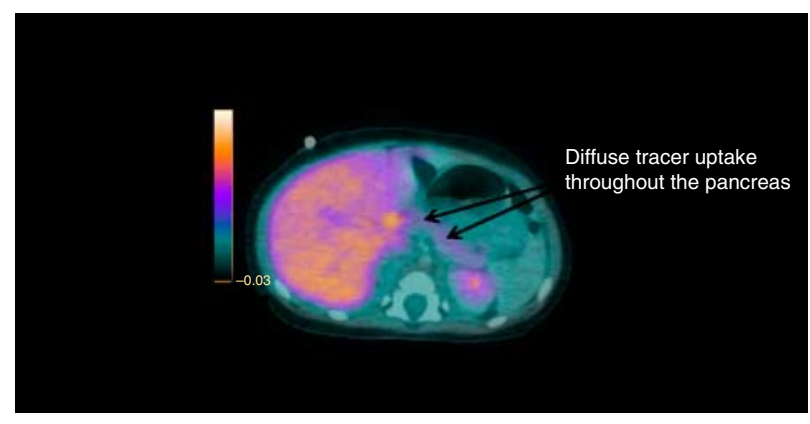

Figure 3

${ }^{18} \mathrm{~F}$ DOPA-PET CT image of patient 40 showing diffuse tracer uptake throughout the pancreas in a patient with paternally inherited heterozygous $A B C C 8$ mutation. Full colour version of this figure available via http://dx.doi.org/10.1530/EJE-14-0353. 
(recessive acting), or lead to focal CHI (if paternally inherited and associated with loss of somatic maternal 11p allele) or diffuse CHI (dominant acting). Diazoxide, a $\mathrm{K}_{\mathrm{ATP}}$ channel opener, which is the first-line management for CHI, is usually ineffective in biallelic disease and monoallelic focal disease $(3,4)$. However, recently a case of diazoxide-responsive focal CHI was described (23). It may be possible that as more diazoxide-responsive $\mathrm{CHI}$ patients are investigated with ${ }^{18} \mathrm{~F}$ DOPA-PET CT scan, more diazoxide-responsive focal lesions are identified. However, currently diazoxide responsiveness in our institution is generally considered equivalent to excluding monoallelic focal disease and this group of patients are not usually considered as suitable candidates for further investigations with ${ }^{18} \mathrm{~F}$ DOPA-PET CT. On the other hand, diazoxideunresponsive subgroup, particularly associated with paternally inherited monoallelic $A B C C 8 / K C N J 11$ mutations or no identified $A B C C 8 / K C N J 11$ mutations, is investigated with ${ }^{18} \mathrm{~F}$ DOPA-PET CT to identify focal or diffuse subtype before proceeding with definitive treatment as the treatment for focal (limited pancreatectomy) and diffuse $\mathrm{CHI}$ (near-total pancreatectomy) is drastically different (38).

In our cohort of $53 \mathrm{CHI}$ patients associated with paternally inherited monoallelic ABCC8/KCNJ11 mutations, 18 (33\%) patients either responded to diazoxide or resolved spontaneously and are likely to have dominant acting CHI. Mutations in these 18 patients are predicted to be pathogenic by different mutation prediction programmes (Table 2). Functional work has already established some of these mutants to be dominant acting and exerting their effect by a dominant-negative mechanism $(33,39,40)$. Although there was no history of hypoglycaemia in the fathers of our cohort, formal evaluation with controlled provocation fasting studies has not been done. Other studies also have reported parents to be asymptomatic carriers of dominant acting mutations (41). In view of severe diazoxide side effects and parental request, three patients from this subgroup underwent ${ }^{18} \mathrm{~F}$ DOPA-PET CT imaging to avoid long-term treatment with diazoxide. This was in the hope that these patients could be managed with removal of focal lesion if found to be the underlying cause for $\mathrm{CHI}$. However, as suspected from the phenotype of diazoxide-responsiveness, ${ }^{18} \mathrm{~F}$ DOPA-PET CT identified diffuse tracer uptake throughout the pancreas.

Evaluation with ${ }^{18} \mathrm{~F}$ DOPA-PET CT in 27 diazoxideunresponsive patients with paternally inherited heterozygous $A B C C 8 / K C N J 11$ mutations identified focal disease in $21(78 \%)$ patients. Majority of these patients presented within the first week of life. There was no difference in the age of presentation between those who were diagnosed with diffuse or focal CHI. Apart from one patient who was managed with octreotide therapy, these patients were either managed with resection of the focal lesion or partial pancreatectomy. Follow-up assessment highlighted ageappropriate fasting tolerance and resolution of hypoglycaemia in all except one $(19 / 20 ; 95 \%)$ after the removal of the focal lesion. Similar to our results, Lord et al. (42) recently reported that $94 \%$ of their cohort of focal CHI after pancreatectomy remained euglycaemic and required no treatment for blood glucose abnormalities. In the cohort reported by Beltrand et al. (43), 91.4\% (43/47) patients with focal $\mathrm{CHI}$ had complete resolution of hypoglycaemia post-surgery. One patient in whom the evidence of CHI persisted despite the removal of a histologically confirmed focal lesion was managed with diazoxide and regular feeds. A repeat ${ }^{18} \mathrm{~F}$ DOPA-PET CT revealed diffuse tracer uptake in the remaining pancreas. Molecular basis for $\mathrm{CHI}$ in this particular patient is unclear and further studies are in progress.

In six (21\%) diazoxide-unresponsive patients investigated with ${ }^{18} \mathrm{~F}$ DOPA-PET CT, diffuse tracer uptake throughout the pancreas was noticed (Fig. 3). Three of these patients were managed with near-total pancreatectomy and in one of these patients, histology and microsatellite analysis was suggestive of giant focal lesion (44). Diffuse uptake in this particular patient was due to the size of the focal lesion, which occupied nearly the whole pancreas. Diffuse $\mathrm{CHI}$ has been described in the literature with paternally inherited $A B C C 8 / K C N J 11$ mutations. Fernandez-Marmiesse et al. (10) reported five patients with paternally inherited $\mathrm{K}_{\mathrm{ATP}}$ mutations and whose post pancreatectomy pathology result was not consistent with that of focal lesion. Similar findings have been reported by other studies $(1,21,27,30)$.

There are a number of possible mechanisms as to how a heterozygous $A B C C 8 / K C N J 11$ mutation can lead to diffuse disease. For example there could be a post-zygotic second hit within the pancreas or a maternally inherited mutation may reside within a non-coding regulatory/intronic region of the $A B C C 8 / K C N J 11$ gene. Recently, in a patient with focal CHI but no exonic or splice site $A B C C 8 / K C N J 11$ mutation, nextgeneration sequencing identified a deep intronic $A B C C 8$ mutation inherited from the unaffected father, which created a cryptic spice site and an out of frame pseudoexon (32). A third possibility is allelic drop-out due to a rare polymorphism within a primer binding site. In this scenario, a maternally inherited coding mutation could escape detection by Sanger sequencing. Besides, some of the missense mutations may be dominantly acting (dominant negative). 
As compared with recessive acting mutations where there is defective biogenesis or trafficking of $\mathrm{K}_{\mathrm{ATP}}$ channel to the $\beta$-cell membrane, the dominant acting mutants traffic normally to the plasma membrane but show impaired responsiveness to the channel agonists, MgADP and diazoxide (45). Diazoxide-unresponsive mutations produce a more severe impairment in the expressed channel response to activation by diazoxide and MgADP as compared with diazoxide-responsive mutations (28).

A novel genetic mechanism of diffuse disease due to mosaic paternal uniparental isodisomy in a patient with heterozygous $A B C C 8 / K C N J 11$ mutations was recently described (36). Lastly, it could also very rarely be due to failure of Sanger sequencing to detect the second $A B C C 8 / K C N J 11$ mutation or a missed histological diagnosis of focal $\mathrm{CHI}$ in these patients. Although $A B C C 8$ and KCNJ11 are not known to be imprinted genes, they are next to the $11 \mathrm{p} 15.5$ imprinted region, so another hypothesis could be the involvement of epigenetic mechanisms.

In summary, of the 53 patients associated with paternally inherited $A B C C 8 / K C N J 11$ mutations, 29 (55\%) patients had diffuse CHI (18 (34\%) patients - diazoxideresponsive; 11 (21\%) patients - diazoxide-unresponsive) and $24(45 \%)$ patients had confirmed focal CHI either based on histology or LOH studies. One patient had giant focal lesion based on histology and LOH studies, confusing the interpretation of ${ }^{18} \mathrm{~F}$ DOPA-PET CT. From our results, it is clear that paternally inherited heterozygous $A B C C 8 / K C N J 11$ mutations can manifest as a wide spectrum of $\mathrm{CHI}$ with focal disease in $45 \%$ patients. This heterogeneous clinical picture could be due to modifying genes or other unknown factors, e.g. environmental, that influence the expression of the phenotype in CHI patients.

\section{Declaration of interest}

The authors declare that there is no conflict of interest that could be perceived as prejudicing the impartiality of the research reported.

\section{Funding}

This research did not receive any specific grant from any funding agency in the public, commercial or not-for-profit sector

\section{References}

1 Senniappan S, Shanti B, James C \& Hussain K. Hyperinsulinaemic hypoglycaemia: genetic mechanisms, diagnosis and management.
Journal of Inherited Metabolic Disease 201235 589-601. (doi:10.1007/ s10545-011-9441-2)

2 Kapoor RR, Flanagan SE, James C, Shield J, Ellard S \& Hussain K. Hyperinsulinaemic hypoglycaemia. Archives of Disease in Childhood 200994 450-457. (doi:10.1136/adc.2008.148171)

3 Kapoor RR, Flanagan SE, Arya VB, Shield JP, Ellard S \& Hussain K. Clinical and molecular characterisation of 300 patients with congenital hyperinsulinism. European Journal of Endocrinology 2013168 557-564. (doi:10.1530/EJE-12-0673)

4 Snider KE, Becker S, Boyajian L, Shyng SL, MacMullen C, Hughes N, Ganapathy K, Bhatti T, Stanley CA \& Ganguly A. Genotype and phenotype correlations in 417 children with congenital hyperinsulinism. Journal of Clinical Endocrinology and Metabolism 201398 E355-E363. (doi:10.1210/jc.2012-2169)

5 Nestorowicz A, Wilson BA, Schoor KP, Inoue H, Glaser B, Landau H, Stanley CA, Thornton PS, Clement JP, Bryan J et al. Mutations in the sulonylurea receptor gene are associated with familial hyperinsulinism in Ashkenazi Jews. Human Molecular Genetics 19965 1813-1822. (doi:10.1093/hmg/5.11.1813)

6 Greer RM, Shah J, Jeske YW, Brown D, Walker RM, Cowley D, Bowling FG, Liaskou D, Harris M, Thomsett MJ et al. Genotypephenotype associations in patients with severe hyperinsulinism of infancy. Pediatric and Developmental Pathology 200710 25-34. (doi:10.2350/06-04-0083.1)

7 Darendeliler F, Fournet JC, Bas F, Junien C, Gross MS, Bundak R, Saka N \& Gunoz H. ABCC8 (SUR1) and KCNJ11 (KIR6.2) mutations in persistent hyperinsulinemic hypoglycemia of infancy and evaluation of different therapeutic measures. Journal of Pediatric Endocrinology \& Metabolism 200215 993-1000.

8 Tornovsky S, Crane A, Cosgrove KE, Hussain K, Lavie J, Heyman M, Nesher Y, Kuchinski N, Ben-Shushan E, Shatz O et al.

Hyperinsulinism of infancy: novel ABCC8 and KCNJ11 mutations and evidence for additional locus heterogeneity. Journal of Clinical Endocrinology and Metabolism 200489 6224-6234. (doi:10.1210/ jc.2004-1233)

9 Gloyn AL, Siddiqui J \& Ellard S. Mutations in the genes encoding the pancreatic $\beta$-cell $\mathrm{K}_{\mathrm{ATP}}$ channel subunits Kir6.2 (KCNJ11) and SUR1 (ABCC8) in diabetes mellitus and hyperinsulinism. Human Mutation 200627 220-231. (doi:10.1002/humu.20292)

10 Fernandez-Marmiesse A, Salas A, Vega A, Fernandez-Lorenzo JR, Barreiro J \& Carracedo A. Mutation spectra of ABCC8 gene in Spanish patients with Hyperinsulinism of Infancy (HI). Human Mutation 2006 27 214. (doi:10.1002/humu.9401)

11 Shimomura K, Flanagan SE, Zadek B, Lethby M, Zubcevic L, Girard CA, Petz O, Mannikko R, Kapoor RR, Hussain K et al. Adjacent mutations in the gating loop of Kir6.2 produce neonatal diabetes and hyperinsulinism. EMBO Molecular Medicine 20091 166-177. (doi:10.1002/ emmm.200900018)

12 Muzyamba M, Farzaneh T, Behe P, Thomas A, Christesen HB, Brusgaard K, Hussain K \& Tinker A. Complex ABCC8 DNA variations in congenital hyperinsulinism: lessons from functional studies. Clinical Endocrinology 200767 115-124. (doi:10.1111/j.1365-2265. 2007.02847.x)

13 Otonkoski T, Nanto-Salonen K, Seppanen M, Veijola R, Huopio H, Hussain K, Tapanainen P, Eskola O, Parkkola R, Ekstrom K et al. Noninvasive diagnosis of focal hyperinsulinism of infancy with $\left[{ }^{18} \mathrm{~F}\right]$-DOPA positron emission tomography. Diabetes 200655 13-18. (doi:10.2337/diabetes.55.01.06.db05-1128)

14 Kassem SA, Ariel I, Thornton PS, Hussain K, Smith V, Lindley KJ, Aynsley-Green A \& Glaser B. p57(KIP2) expression in normal islet cells and in hyperinsulinism of infancy. Diabetes $2001502763-2769$ (doi:10.2337/diabetes.50.12.2763)

15 Suchi M, MacMullen C, Thornton PS, Ganguly A, Stanley CA \& Ruchelli ED. Histopathology of congenital hyperinsulinism: retrospective study with genotype correlations. Pediatric and 
Developmental Pathology 20036 322-333. (doi:10.1007/s10024002-0026-9)

16 Damaj L, le Lorch M, Verkarre V, Werl C, Hubert L, Nihoul-Fekete C, Aigrain Y, de Keyzer Y, Romana SP, Bellanne-Chantelot C et al. Chromosome 11p15 paternal isodisomy in focal forms of neonatal hyperinsulinism. Journal of Clinical Endocrinology and Metabolism 2008 93 4941-4947. (doi:10.1210/jc.2008-0673)

17 Verkarre V, Fournet JC, de Lonlay P, Gross-Morand MS, Devillers M, Rahier J, Brunelle F, Robert JJ, Nihoul-Fekete C, Saudubray JM et al. Paternal mutation of the sulfonylurea receptor (SUR1) gene and maternal loss of 11p15 imprinted genes lead to persistent hyperinsulinism in focal adenomatous hyperplasia. Journal of Clinical Investigation 1998102 1286-1291. (doi:10.1172/JCI4495)

18 Calton EA, Temple IK, Mackay DJ, Lever M, Ellard S, Flanagan SE, Davies JH, Hussain K \& Gray JC. Hepatoblastoma in a child with a paternally-inherited ABCC8 mutation and mosaic paternal uniparental disomy $11 \mathrm{p}$ causing focal congenital hyperinsulinism. European Journal of Medical Genetics 201356 114-117. (doi:10.1016/j.ejmg.2012. 12.001)

19 Shuman C, Smith AC, Steele L, Ray PN, Clericuzio C, Zackai E, Parisi MA, Meadows AT, Kelly T, Tichauer D et al. Constitutional UPD for chromosome $11 \mathrm{p} 15$ in individuals with isolated hemihyperplasia is associated with high tumor risk and occurs following assisted reproductive technologies. American Journal of Medical Genetics. Part A 2006140 1497-1503. (doi:10.1002/ajmg.a.31323)

20 Giurgea I, Bellanne-Chantelot C, Ribeiro M, Hubert L, Sempoux C, Robert JJ, Blankenstein O, Hussain K, Brunelle F, Nihoul-Fekete C et al. Molecular mechanisms of neonatal hyperinsulinism. Hormone Research 200666 289-296. (doi:10.1159/000095938)

21 Fournet JC, Verkarre V, De Lonlay P, Rahier J, Brunelle F, Robert JJ, Nihoul-Fekete C, Saudubray JM \& Junien C. Loss of imprinted genes and paternal SUR1 mutations lead to hyperinsulinism in focal adenomatous hyperplasia. Annales d'Endocrinologie 199859 485-491.

22 de Lonlay P, Fournet JC, Rahier J, Gross-Morand MS, Poggi-Travert F, Foussier V, Bonnefont JP, Brusset MC, Brunelle F, Robert JJ et al. Somatic deletion of the imprinted 11p15 region in sporadic persistent hyperinsulinemic hypoglycemia of infancy is specific of focal adenomatous hyperplasia and endorses partial pancreatectomy. Journal of Clinical Investigation 1997100 802-807. (doi:10.1172/JCI119594)

23 Maiorana A, Barbetti F, Boiani A, Rufini V, Pizzoferro M, Francalanci P, Faletra F, Nichols CG, Grimaldi C, de Ville de Goyet J et al. Focal congenital hyperinsulinism managed by medical treatment: a diagnostic algorithm based on molecular genetic screening. Clinical Endocrinology 2014. In press. (doi:10.1111/cen.12400)

24 Hardy OT, Hernandez-Pampaloni M, Saffer JR, Scheuermann JS, Ernst LM, Freifelder R, Zhuang H, MacMullen C, Becker S, Adzick NS et al. Accuracy of $\left[{ }^{18} \mathrm{~F}\right]$ fluorodopa positron emission tomography for diagnosing and localizing focal congenital hyperinsulinism. Journal of Clinical Endocrinology and Metabolism 200792 4706-4711. (doi:10.1210/ jc.2007-1637)

25 Stanley CA, Thornton PS, Ganguly A, MacMullen C, Underwood P, Bhatia P, Steinkrauss L, Wanner L, Kaye R, Ruchelli E et al. Preoperative evaluation of infants with focal or diffuse congenital hyperinsulinism by intravenous acute insulin response tests and selective pancreatic arterial calcium stimulation. Journal of Clinical Endocrinology and Metabolism 200489 288-296. (doi:10.1210/jc.2003-030965)

26 de Lonlay-Debeney P, Poggi-Travert F, Fournet JC, Sempoux C, Vici CD, Brunelle F, Touati G, Rahier J, Junien C, Nihoul-Fekete C et al. Clinical features of 52 neonates with hyperinsulinism. New England Journal of Medicine 1999340 1169-1175. (doi:10.1056/ NEJM199904153401505)

27 Blomberg BA, Moghbel MC, Saboury B, Stanley CA \& Alavi A. The value of radiologic interventions and (18)F-DOPA PET in diagnosing and localizing focal congenital hyperinsulinism: systematic review and meta-analysis. Molecular Imaging and Biology 201315 97-105. (doi:10.1007/s11307-012-0572-0)
28 Macmullen CM, Zhou Q, Snider KE, Tewson PH, Becker SA, Aziz AR, Ganguly A, Shyng SL \& Stanley CA. Diazoxide-unresponsive congenital hyperinsulinism in children with dominant mutations of the $\beta$-cell sulfonylurea receptor SUR1. Diabetes 201160 1797-1804. (doi:10.2337/ db10-1631)

29 Bellanne-Chantelot C, Saint-Martin C, Ribeiro MJ, Vaury C, Verkarre V, Arnoux JB, Valayannopoulos V, Gobrecht S, Sempoux C, Rahier J et al. ABCC8 and KCNJ11 molecular spectrum of 109 patients with diazoxide-unresponsive congenital hyperinsulinism. Journal of Medical Genetics 201047 752-759. (doi:10.1136/jmg.2009.075416)

30 Mohnike K, Wieland I, Barthlen W, Vogelgesang S, Empting S, Mohnike W, Meissner T \& Zenker M. Clinical and genetic evaluation of patients with $\mathrm{K}$ channel mutations from the German registry for congenital hyperinsulinism. Hormone Research in Paediatrics 201481 156-168. (doi:10.1159/000356905)

31 Meintjes M, Endozo R, Dickson J, Erlandsson K, Hussain K, Townsend C, Menezes L \& Bomanji J. ${ }^{18} \mathrm{~F}$-DOPA PET enhanced CT imaging for congenital hyperinsulinism: initial UK experience from a technologist's perspective. Nuclear Medicine Communications 201334 601-608. (doi:10.1097/MNM.0b013e32836069d0)

32 Flanagan SE, Xie W, Caswell R, Damhuis A, Vianey-Saban C, Akcay T, Darendeliler F, Bas F, Guven A, Siklar Z et al. Next-generation sequencing reveals deep intronic cryptic ABCC8 and HADH splicing founder mutations causing hyperinsulinism by pseudoexon activation. American Journal of Human Genetics 201392 131-136. (doi:10.1016/ j.ajhg.2012.11.017)

33 Huopio H, Reimann F, Ashfield R, Komulainen J, Lenko HL, Rahier J, Vauhkonen I, Kere J, Laakso M, Ashcroft F et al. Dominantly inherited hyperinsulinism caused by a mutation in the sulfonylurea receptor type 1 . Journal of Clinical Investigation 2000106 897-906. (doi:10.1172/JCI9804)

34 Schwarz JM, Rodelsperger C, Schuelke M \& Seelow D. MutationTaster evaluates disease-causing potential of sequence alterations. Nature Methods 20107 575-576. (doi:10.1038/nmeth0810-575)

35 Choi Y, Sims GE, Murphy S, Miller JR \& Chan AP. Predicting the functional effect of amino acid substitutions and indels. PLOS ONE 2012 7 e46688. (doi:10.1371/journal.pone.0046688)

36 Hussain K, Flanagan SE, Smith VV, Ashworth M, Day M, Pierro A \& Ellard S. An ABCC8 gene mutation and mosaic uniparental isodisomy resulting in atypical diffuse congenital hyperinsulinism. Diabetes 2008 57 259-263. (doi:10.2337/db07-0998)

37 Flanagan S, Damhuis A, Banerjee I, Rokicki D, Jefferies C, Kapoor R, Hussain K \& Ellard S. Partial ABCC8 gene deletion mutations causing diazoxide-unresponsive hyperinsulinaemic hypoglycaemia. Pediatric Diabetes 201213 285-289. (doi:10.1111/j.1399-5448.2011. 00821.x)

38 Banerjee I, Skae M, Flanagan SE, Rigby L, Patel L, Didi M, Blair J, Ehtisham S, Ellard S, Cosgrove KE et al. The contribution of rapid $\mathrm{K}_{\mathrm{ATP}}$ channel gene mutation analysis to the clinical management of children with congenital hyperinsulinism. European Journal of Endocrinology 2011 164 733-740. (doi:10.1530/EJE-10-1136)

39 Kapoor RR, Flanagan SE, James CT, McKiernan J, Thomas AM, Harmer SC, Shield JP, Tinker A, Ellard S \& Hussain K. Hyperinsulinaemic hypoglycaemia and diabetes mellitus due to dominant ABCC8/KCNJ11 mutations. Diabetologia 201154 2575-2583. (doi:10.1007/s00125-011-2207-4)

40 Thornton PS, MacMullen C, Ganguly A, Ruchelli E, Steinkrauss L, Crane A, Aguilar-Bryan L \& Stanley CA. Clinical and molecular characterization of a dominant form of congenital hyperinsulinism caused by a mutation in the high-affinity sulfonylurea receptor. Diabetes 200352 2403-2410. (doi:10.2337/ diabetes.52.9.2403)

41 Pinney SE, MacMullen C, Becker S, Lin YW, Hanna C, Thornton P, Ganguly A, Shyng SL \& Stanley CA. Clinical characteristics and biochemical mechanisms of congenital hyperinsulinism associated with dominant $\mathrm{K}_{\mathrm{ATP}}$ channel mutations. Journal of Clinical Investigation 2008118 2877-2886. (doi:10.1172/JCI35414) 
42 Lord K, Dzata E, Snider KE, Gallagher PR \& De Leon DD. Clinical presentation and management of children with diffuse and focal hyperinsulinism: a review of 223 cases. Journal of Clinical Endocrinology and Metabolism 201398 E1786-E1789. (doi:10.1210/jc.2013-2094)

43 Beltrand J, Caquard M, Arnoux JB, Laborde K, Velho G, Verkarre V, Rahier J, Brunelle F, Nihoul-Fekete C, Saudubray JM et al. Glucose metabolism in 105 children and adolescents after pancreatectomy for congenital hyperinsulinism. Diabetes Care 201235 198-203. (doi:10.2337/dc11-1296)
44 Ismail D, Kapoor RR, Smith VV, Ashworth M, Blankenstein O, Pierro A, Flanagan SE, Ellard S \& Hussain K. The heterogeneity of focal forms of congenital hyperinsulinism. Journal of Clinical Endocrinology and Metabolism 201297 E94-E99. (doi:10.1210/jc.2011-1628)

45 Yan FF, Lin YW, MacMullen C, Ganguly A, Stanley CA \& Shyng SL. Congenital hyperinsulinism associated ABCC8 mutations that cause defective trafficking of ATP-sensitive $\mathrm{K}^{+}$channels: identification and rescue. Diabetes 200756 2339-2348. (doi:10.2337/ db07-0150)

Received 1 May 2014

Revised version received 28 July 2014

Accepted 8 September 2014 